\title{
Late left atrial thrombosis of an Amplatzer patent foramen ovale occluder
}

\author{
Stefan Klotz, MD, ${ }^{a}$ Maximillian Gebhard, MD, ${ }^{\mathrm{b}}$ and Hans H. Sievers, MD ${ }^{\mathrm{a}}$
}

In February 2007, a 51-year-old man was admitted to the neurology department with aphasia. Diagnostic examination revealed a patent foramen ovale (PFO) that was successfully occluded with an Amplatzer occluder (AGA Medical Corp, Plymouth, Minn) in March of 2007. The postoperative course was uneventful. He received oral therapy with aspirin and Coumadin for 6 months.

Two and a half years later in December 2010, the patient returned to the hospital with aphasia. Cerebral computer scan showed a left frontal 9- $\times 7$-mm lesion. Further diagnostic examination with transesophageal echocardiography revealed a huge mass in the left atrium directly on top of the Amplatzer occluder. A thrombus was suspected, so therapy with heparin and concomitant Coumadin (Bristol-Myers Squibb, New York, NY) was initiated. A complete hematologic survey, including platelet function and coagulation factors, showed no pathologic findings. In February 2011, transesophageal echocardiography verified that the left atrial mass had progressed (Figure 1). Magnetic resonance tomography could not distinguish between thrombus and myxoma, so cardiac surgery was scheduled.

During cardiac surgery, the Amplatzer PFO occluder and the left atrial mass were excised completely (Figure 2). The septal defect was closed with pericardium. The postoperative course was uneventful. Histology revealed an organized thrombus with proliferating connective tissue and capillaries (Figure 3).

\section{DISCUSSION}

Interventional occlusion for PFO is a standard procedure. Whether this is beneficial in contrast with medical therapy alone in patients with cryptogenic stroke will be analyzed. ${ }^{1}$ Although right atrial thrombosis of an Amplatzer occluder has been reported, ${ }^{2}$ thrombosis in the left atrium has not been. In a large series of 620 patients with the Amplatzer PFO occluder for secondary prevention of paradoxical embolism, only 2 small thrombi were seen on the atrial disk at 6-month follow-up, which resolved with oral

\footnotetext{
From the Department of Cardiac and Thoracic Vascular Surgery ${ }^{\mathrm{a}}$ and Institute of Pathology, ${ }^{\mathrm{b}}$ University Hospital Luebeck, Germany.

Disclosures: Authors have nothing to disclose with regard to commercial support.

Received for publication May 23, 2011; accepted for publication May 25, 2011; available ahead of print July 4, 2011.

Address for reprints: Stefan Klotz, MD, Department of Cardiac and Thoracic Vascular Surgery, University Hospital Luebeck Ratzeburger Allee 16023538 Luebeck, Germany (E-mail: Stefan.Klotz@uk-sh.de).

J Thorac Cardiovasc Surg 2011;142:1270-1

$0022-5223 / \$ 36.00$

Copyright (C) 2011 by The American Association for Thoracic Surgery doi:10.1016/j.jtcvs.2011.05.024
}

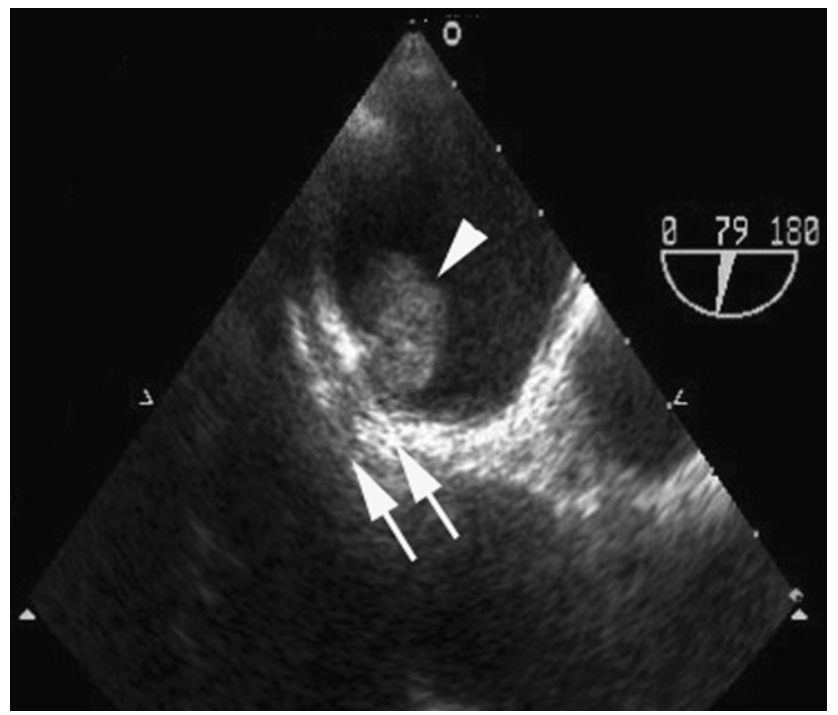

FIGURE 1. Transesophageal echocardiography shows the PFO Amplatzer occluder (AGA Medical Corp, Plymouth, Minn) (double arrow) with a mass in the left atrium (arrowhead).

anticoagulation. No thrombus was seen after a median follow-up of 2.6 years. ${ }^{3}$

\section{CONCLUSIONS}

This report describes a late large thrombosis of the atrial disk of an Amplatzer PFO occluder implanted 33 months after the initial implantation.

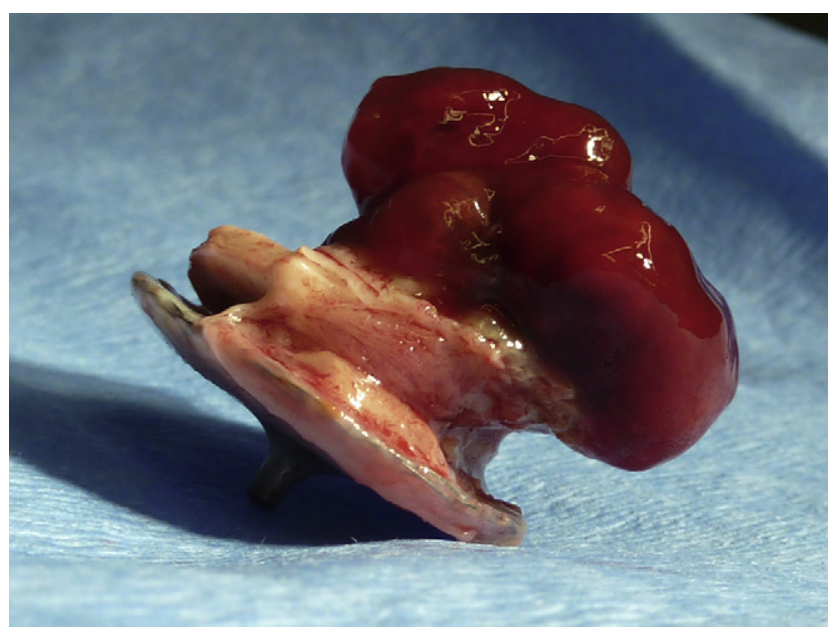

FIGURE 2. Explanted device with the mass sitting on the left atrial disk. 


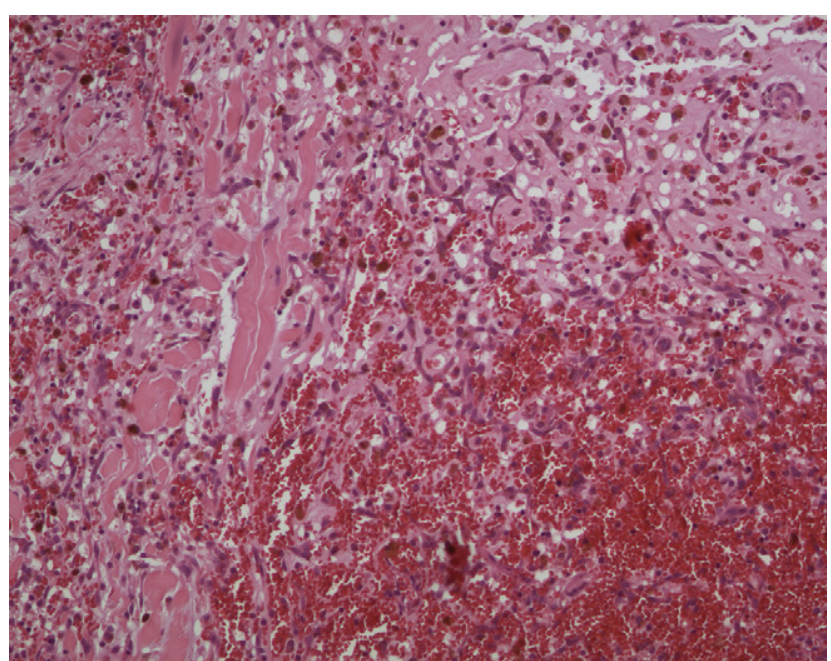

FIGURE 3. Histology of the organized thrombus.

\section{References}

1. Khattab AA, Windecker S, Juni P, et al. Randomized clinical trial comparing percutaneous closure of patent foramen ovale (PFO) using the Amplatzer PFO occluder with medical treatment in patients with cryptogenic embolism (PC-Trial): rationale and design. Trials. 2011;12:56.

2. Vigna C, Mazzoccoli GL, Santoro T, Di EG, Loperfido F. Pulmonary embolism: a late complication of a correctly positioned occluder device for patent foramen ovale. J Cardiovasc Med (Hagerstown). 2008;9:1057-8.

3. Wahl A, Tai T, Praz F, et al. Late results after percutaneous closure of patent foramen ovale for secondary prevention of paradoxical embolism using the Amplatzer PFO occluder without intraprocedural echocardiography: effect of device size. JACC Cardiovasc Interv. 2009;2:116-23. 